\title{
Virulence Characterization of Venturia inaequalis Reference Isolates on the Differential Set of Malus Hosts
}

Valérie Caffier, INRA, UMR1345 Institut de Recherche en Horticulture et Semences, 49071 Beaucouzé, France; AgroCampus-Ouest, UMR1345 Institut de Recherche en Horticulture et Semences, 49045 Angers, France; Université d'Angers, UMR1345 Institut de Recherche en Horticulture et Semences, SFR 4207 QUASAV, 49045 Angers, France; Andrea Patocchi, Agroscope Research Station, Phytopathology, P.B., 8820 Wädenswil, Switzerland; Pascale Expert, Marie-Noëlle Bellanger, and Charles-Eric Durel, INRA, UMR1345 Institut de Recherche en Horticulture et Semences, 49071 Beaucouzé, France; AgroCampus-Ouest, UMR1345 Institut de Recherche en Horticulture et Semences, 49045 Angers, France; Université d'Angers, UMR1345 Institut de Recherche en Horticulture et Semences, SFR 4207 QUASAV, 49045 Angers, France; Maja Hilber-Bodmer, Agroscope Research Station, Phytopathology, P.B., 8820 Wädenswil, Switzerland; Giovanni A. L. Broggini, Agroscope Research Station, Phytopathology, P.B., 8820 Wädenswil, Switzerland; Swiss Federal Institute of Technology Zürich ETHZ, Phytopathology Group, Universitätstrasse 2, Zürich, Switzerland; Remmelt Groenwold, Wageningen University and Research, Plant Breeding, P.O. Box 16, 6700AA Wageningen, The Netherlands; and Vincent G. M. Bus, The New Zealand Institute for Plant \& Food Research Limited, Private Bag 1401, Havelock North 4157, New Zealand

\begin{abstract}
Caffier, V., Patocchi, A., Expert, P., Bellanger, M. N., Durel, C. E., Hilber-Bodmer, M., Broggini, G. A. L., Groenwold, R., and Bus, V. G. M. 2015. Virulence characterization of Venturia inaequalis reference isolates on the differential set of Malus hosts. Plant Dis. 99:370-375.

A set of differential hosts has recently been identified for 17 apple scab resistance genes in an updated system for defining gene-for-gene (GfG) relationships in the Venturia inaequalis-Malus pathosystem. However, a set of reference isolates characterized for their complementary avirulence alleles is not yet available. In this paper, we report on improving the set of differential hosts for $\mathrm{h}(7)$ and propose the apple genotype LPG3-29 as carrying the single major resistance gene Rvi7. We characterized a reference set of $23 \mathrm{~V}$. inaequalis isolates on 14 differential apple hosts carrying major resistance genes under con-

one of the following defined resistance gene hosts: $h(1), h(2), h(3)$, $h(4), h(5), h(6), h(7), h(8), h(9), h(10)$, and $h(13)$. Sixteen different virulence patterns were observed. In general, the isolates carried one to three virulences, but some of them were more complex, with up to six virulences. This set of well-characterized isolates will be helpful for the identification of additional apple scab resistance genes in apple germplasm and the characterization of new GfG relationships to help improve our understanding of the host-pathogen interactions in the $V$. inaequalis-Malus pathosystem.
\end{abstract} trolled conditions. We identified isolates that were virulent on at least
Durable pest and disease resistance is a major breeding objective for most crops, but achieving it has proven to be a challenge for breeders in the absence of truly non-race-specific resistances. Many genes involved in effector-triggered immunity (20) code for highly polymorphic proteins containing nucleotide binding (NB) and leucine-rich repeat (LRR) domains that induce a resistance reaction in the host following recognition of the complementary pathogen effector protein(s) in this specific gene-for-gene (GfG) relationship (13). However, the high evolutionary potential of the pathogen effector arsenal negatively affects the durability of resistance genes. To counteract, or at least delay the breakdown of resistance genes by virulent races of the pathogen, breeders search for new resistance genes (major genes and quantitative trait loci [QTLs]) that are effective against the already known virulent races $(21,23)$ and pyramid them (including "spent" ones) to improve their durability as well as increase the efficacy of the combined genes. This is based on the principle that for a multiple virulent strain to develop, it will have to acquire these virulences simultaneously (11). The effectiveness of this strategy relies on the availability of a set of differential hosts and reference isolates to understand the genetics of the arsenal of both effectors in the

Corresponding author: V. Caffier, E-mail: valerie.caffier@ angers.inra.fr

The first two authors contributed equally to this work.

Accepted for publication 14 September 2014.

http://dx.doi.org/10.1094/PDIS-07-14-0708-RE

(C) 2015 The American Phytopathological Society pathogen and resistances in the host, and their GfG relationships (34).

Apple scab, caused by Venturia inaequalis, is one of the main diseases of apple, which requires 10 to 20 fungicide applications per year for efficient control in the different production regions around the world (3). Resistant apple cultivars provide the opportunity to reduce the use of pesticides and the risk of fungicide resistance in the pathogen (e.g., 9,30), but they have largely relied on single gene resistance conferred by Rvi6, which is now overcome by virulent isolates (16). As a consequence, there is a need for new resistant cultivars with a better potential for durability. The $V$. inaequalis-Malus pathosystem was one for which research on GfG relationships had made considerable progress $(2,35)$ by the time Flor (13) published his findings for the Melampsora lini-Linum usitatissimum pathosystem. To date, $17 \mathrm{GfG}$ relationships have been described (7). More are sure to follow as additional resistance genes and QTLs have been (provisionally) mapped to the apple genome (e.g., 12,15).

Breeders require a good understanding of the genetics of apple scab resistance to preserve known resistance genes, and to identify new ones for breeding. For that purpose, both a set of well-defined differential hosts for known apple scab resistance genes and a set of well-characterized reference isolates are required. Currently, 15 of the 17 differential hosts (7) are being distributed to monitor the virulence distribution of $V$. inaequalis populations in many apple production regions around the world through the VINQUEST initiative (27; www.vinquest.ch). However, a complementary set of $V$. inaequalis reference isolates is not yet available. To date, isolates have commonly been used in genetic experiments for their known specific ability to overcome one of the apple scab resistance genes represented in the differential host set (7). However, their status 
regarding all the other resistance genes is usually not known, which could lead to erroneous conclusions in genetic experiments. A good example is isolate 1639 , which was selected for its ability to overcome the $R v i 2$ gene, but its use as a reference isolate in a number of experiments has demonstrated that it can overcome at least another two genes, Rvis and Rvi9, that map to the same genomic region of apple and condition very similar stellate necrotic resistance reactions $(4,6)$. Now that a better understanding of the genetic complexity of resistance has been developed, apple breeders realize that such a well-characterized set of $V$. inaequalis isolates is an essential tool in assisting them in identifying and characterizing new apple scab resistance genes.

The aim of the present paper was to characterize a reference set of $23 \mathrm{~V}$. inaequalis isolates on 14 differential apple hosts carrying major resistance genes under controlled conditions. In the process, we improved the set of differential hosts by identifying a monogenic host $h(7)$.

\section{Materials and Methods}

Isolates. Twenty-three isolates (Table 1) commonly used in host-pathogen interaction studies were selected to extend the partial information gleaned from these studies. The isolates were sampled from Belgium, Denmark, France, Germany, New Zealand, the Netherlands, the United Kingdom, and the United States of America between the 1960s and 2003, with the base reference cultures currently being held at INRA (France). In particular, isolates 2409 (1774-1) and 2410 (US4) are old races that have been used again in more recent experiments (5). All isolates were conserved in a collection on slopes of malt agar medium $\left(10 \mathrm{~g} \mathrm{l}^{-1}\right.$ cristomalt, Difal, Seysses, France; $15 \mathrm{~g} \mathrm{l}^{-1}$ agar, Merck, Darmstadt, Germany) in tubes at $4^{\circ} \mathrm{C}$. They were multiplied on sheets of cellophane (Hutchinson, Chalette/Loing, France) overlaid on malt agar medium. The cellophane sheets were air-dried and frozen at $-20^{\circ} \mathrm{C}$ until use.

Hosts. The isolates were inoculated on 14 hosts (Table 2) that form part of an existing set of 17 differential hosts and on host $h(0)$ 'Gala' as the susceptible control (7). For most of the apple scab resistance genes examined in this study, presumed single-gene differential hosts were used $(7,14,31)$, acknowledging that additional genes and new GfG relationships may be detected in them in future. In some cases $(h(3), h(10), h(12)$, and $h(14))$, accessions known to carry more than one apple scab resistance gene $(4,7,27)$ were used in the absence of monogenic hosts. For h(7), instead of M. floribunda 821 that carries Rvi6 and Rvi7 (7), we introduce accession LPG3-29 (1), which was selected from a 'Golden Delicious' $\times$ Malus floribunda 821 progeny segregating for the Rvil, Rvi6, and $R v i 7$ genes, based on molecular marker data indicating that it only carries the latter gene (CE Durel, unpublished data). Only a limited number of trees of K2 were ready for testing, while no trees of hosts $h(11), h(16)$, and $h(17)$ were available for this study. Potted clonal trees grown on M.9 or MM.106 rootstock that were produced locally in each country, were used in all experiments.

Pathogenicity tests. Pathogenicity tests were carried out in France (INRA, Angers), Switzerland (Agroscope Research station, Wädenswil), and the Netherlands (Wageningen University and Research, Wageningen). Three differential hosts were tested in both France and Switzerland, three hosts tested in both the Netherlands and France, and one host tested in both the Netherlands and Switzerland (Table 2). Three replicate trees were used to study each host-pathogen interaction. Inoculation was performed when the plants had 10 to 20 leaves.

In France, plants were inoculated by spraying a suspension (22) calibrated to $2.5 \times 10^{5}$ conidia $\mathrm{ml}^{-1}$ till run-off. After inoculation, surface moisture on leaves was maintained with an atomizer for 2 days in darkness at $18^{\circ} \mathrm{C}$, after which the plants were incubated at $18^{\circ} \mathrm{C}$ with $16 \mathrm{~h}$ light and relative humidity fluctuating between 70 and $90 \%$. In Switzerland and the Netherlands, plants were inoculated by pipetting $150 \mu \mathrm{l}$ droplets of conidial suspension (between $0.7 \times 10^{5}$ and $2.9 \times 10^{5}$ spores $\mathrm{ml}^{-1}$ ) into inoculation chambers placed pair-wise on the youngest unfurled leaves at the tip of the shoots, large enough to fit two chambers $(6,8)$. The plants were kept in the dark in plastic tents for 2 days at $18^{\circ} \mathrm{C}$ to establish infection. In Switzerland, this was aided by injecting water vapor (Boneco 7133 Ultrasonic Humidifier) for 15 min every $2 \mathrm{~h}$ to maintain relative humidity at saturation level. After 2 days, the

Table 1. Venturia inaequalis isolates tested in the present study

\begin{tabular}{|c|c|c|c|c|c|c|}
\hline Isolate & Collection $^{a}$ & Sampling date & Country & Host of origin & Host R gene(s) & Reference $^{b}$ \\
\hline 104 & INRA, France & 1978 & France & Golden Delicious & Rvil & 18 \\
\hline 147 & INRA, France & 1985 & France & 9-AR2T196 & Rvi5 & 19 \\
\hline 174 & INRA, France & 1986 & France & 9-A2T128 & Rvi5 & 18 \\
\hline 301 & INRA, France & 1988 & Germany & $81 / 19-53$ & $-f$ & 1 \\
\hline 302 & INRA, France & 1988 & Germany & $81 / 11-22$ & Rvi6 & 24 \\
\hline 405 & INRA, France & 1988 & France & TSR33T239 & Rvi4 & 30 \\
\hline 413 & INRA, France & 1988 & France & TSR34T15 & Rvi2 & g g \\
\hline $1066 \mathrm{e}^{\mathrm{c}}$ & INRA, France & 1993 & United Kingdom & Malus floribunda 821 & Rvi6, Rvi7 & 1 \\
\hline 1127 & INRA, France & 1994 & The Netherlands & Vanda Cleef & Rvi6 & 25 \\
\hline 1634 & INRA, France & 2001 & France & TSR33T239 & Rvi4 & $-\mathrm{g}$ \\
\hline 1638 & INRA, France & 2001 & France & TSR33T239 & Rvi4 & $-g$ \\
\hline 1639 & INRA, France & 2001 & France & TSR34T15 & Rvi2 & 8 \\
\hline 1680 & INRA, France & 2001 & France & Judeline & Rvi6 & g g \\
\hline 2199 & INRA, France & 2003 & Denmark & Florina & Rvi6 & -g \\
\hline $2408(=\mathrm{NZ} 188 \mathrm{~B})$ & PFR, NZ & 2000 & New Zealand & W188B & Rvi8 & 6 \\
\hline $2409(=1774-1)$ & PRI, USA & $<1970$ & USA & unknown & Rvi3? & 5 \\
\hline 2410 (=US4) & PRI, USA & $<1970$ & USA & unknown & Rvi4? & 5 \\
\hline EU-B04 & INRA, France, DARE ${ }^{\mathrm{e}}$ & 1998 & Belgium & Golden Delicious Reinhardt & Rvil & 26 \\
\hline EU-B05 & INRA, France, DARE & 1998 & Belgium & Schone von Boskoop & $-\mathrm{f}$ & 8 \\
\hline EU-D42a ${ }^{d}$ & INRA, France, DARE & 1999 & Germany & Prima & Rvi1, Rvi6 & 26 \\
\hline EU-NL05 & INRA, France, DARE & 1998 & The Netherlands & Malus floribunda 821 & Rvi6, Rvi7 & 26 \\
\hline EU-NL19 & INRA, France, DARE & 1998 & The Netherlands & Golden Delicious & Rvil & 26 \\
\hline EU-NL24 & INRA, France, DARE & 1998 & The Netherlands & Prima & Rvi1, Rvi6 & 26 \\
\hline
\end{tabular}

a INRA = Institut National de la Recherche Agronomique; PFR = Plant and Food Research; PRI = Purdue-Rutgers-Illinois collaboration.

${ }^{\mathrm{b}}$ Earliest known reference describing the Venturia inaequalis isolate.

c Isolated from mass-spore isolate TR50 (29); 1066e is a repeated monospore culture from 1066.

${ }^{\mathrm{d}}$ EU-D42a is a re-isolation from EU-D42.

e DARE = European research program 'Durable Apple Resistance in Europe' (1998-2002).

$\mathrm{f}$ No resistance gene reported in the accession.

g No published reference. 
plants were placed in a closed greenhouse chamber with an air conditioner maintaining a $20^{\circ} \mathrm{C}$ day and $18^{\circ} \mathrm{C}$ night temperature regime. Relative humidity was set at $80 \%$. One week after inoculation, the tent incubation was repeated for 2 days under the same conditions to enhance (susceptible) symptom development. In the Netherlands, automated roof venting system was set at a minimum temperature of $20^{\circ} \mathrm{C}$ in the daytime and a minimum temperature of $14^{\circ} \mathrm{C}$ for nighttime heating.

At the three sites, apple scab disease and resistance symptoms were observed 2 and 3 weeks after inoculation. The resistance symptoms were characterized as hypersensitive response (pinpoints), necrosis, stellate necrosis, chlorosis (7), and/or combinations thereof. An isolate is considered to be avirulent if it induces resistance symptoms (incompatible interaction), either with or without limited sporulation. A truly virulent isolate does not induce any resistance reaction on the host, but shows abundant sporulation (compatible interaction). The race spectrum of an isolate is defined by the combination of resistance genes it can overcome (7).

\section{Results}

All isolates were pathogenic as all of them infected $\mathrm{h}(0)$ by producing sporulating lesions in at least one of the three test locations. Most of the interactions tested in the different locations gave similar results (Table 3). However, the inoculations of isolates 174 on $\mathrm{h}(0)$ and $\mathrm{h}(5)$, and 2410 (US4) on $\mathrm{h}(0)$ resulted in variable interactions from compatibility (sporulating lesions without any resistance reaction) to incompatibility (pin-points, Fig. 1) depending on the test.

For the differential hosts carrying major resistance genes, only h(1) 'Golden Delicious' was highly susceptible as only five out of

Table 2. Description of the apple differential hosts used to determine the host-pathogen interactions following inoculation with Venturia inaequalis isolates in three different locations

\begin{tabular}{|c|c|c|c|c|c|c|}
\hline Differential host & Apple accession ${ }^{a}$ & Resistance phenotype & Resistance locus & $\begin{array}{l}\text { Tested in } \\
\text { France }\end{array}$ & $\begin{array}{c}\text { Tested in } \\
\text { Switzerland }\end{array}$ & $\begin{array}{l}\text { Tested in The } \\
\text { Netherlands }\end{array}$ \\
\hline $\mathrm{h}(0)$ & Gala & Susceptibility & - & $\mathrm{x}$ & $\mathrm{x}$ & $\mathrm{x}$ \\
\hline $\mathrm{h}(1)$ & Golden Delicious & Necrosis & Rvil & $\mathrm{x}$ & $\mathrm{x}$ & \\
\hline$h(2)$ & TSR34T15 & Stellate necrosis & Rvi2 & $\mathrm{x}$ & & \\
\hline$h(3)$ & Geneva & Stellate necrosis & Rvi3+?c & $\mathrm{x}$ & & $\mathrm{x}$ \\
\hline $\mathrm{h}(4)$ & TSR33T239 & Hypersensitive response & Rvi4 & $\mathrm{x}$ & & \\
\hline $\mathrm{h}(5)$ & 9-AR2T196 & Hypersensitive response & Rvi5 & $\mathrm{x}$ & & $\mathrm{x}$ \\
\hline$h(6)$ & Priscilla & Chlorosis & Rvi6 & $\mathrm{x}$ & & \\
\hline$h(7)$ & LPG3-29b & Hypersensitive response & Rvi7 & $\mathrm{x}$ & & \\
\hline $\mathrm{h}(8)$ & B45 & Stellate necrosis & Rvi8 & & $\mathrm{x}$ & \\
\hline $\mathrm{h}(9)$ & $\mathrm{K} 2$ & Stellate necrosis & Rvi9 & & & $\mathrm{x}$ \\
\hline $\mathrm{h}(10)$ & A723-6 & Hypersensitive response & Rvilo+?c & & $\mathrm{x}$ & \\
\hline$h(12)$ & Hansen's baccata \#2 & Chlorosis & Rvi12+?c & & $\mathrm{x}$ & \\
\hline$h(13)$ & Durello di Forlì & Stellate necrosis & Rvi13 & & $\mathrm{x}$ & \\
\hline $\mathrm{h}(14)$ & Dülmener Rosenapfel & Chlorosis & Rvil4+?c & $\mathrm{x}$ & $\mathrm{x}$ & \\
\hline$h(15)$ & GMAL2473 & Hypersensitive response & Rvi15 & & $\mathrm{x}$ & \\
\hline
\end{tabular}

a Apple accessions proposed as differential hosts by Bus et al. (7). See this reference for the pedigrees of the differential hosts.

b New differential host h(7), carrying the single resistance gene Rvi7 (instead of $M$. floribunda carrying $R v i 6+R v i 7$ ).

c Presence of additional unknown resistance gene(s).

Table 3. Description of the host-pathogen interactions after inoculation of 23 isolates of Venturia inaequalis on susceptible host h(0) and 14 apple differential hosts

\begin{tabular}{|c|c|c|c|c|c|c|c|c|c|c|c|c|c|c|c|c|c|c|c|c|c|}
\hline \multirow[b]{2}{*}{ Isolate } & \multicolumn{3}{|c|}{$\mathbf{h}(\mathbf{0})$} & \multicolumn{2}{|c|}{ h(1) } & \multirow{2}{*}{$\frac{h(2)}{F}$} & \multicolumn{2}{|c|}{$h(3)$} & \multirow{2}{*}{$\frac{h(4)}{F}$} & \multicolumn{2}{|c|}{$h(5)$} & \multirow{2}{*}{$\frac{\mathbf{h}(\mathbf{6})}{\mathrm{F}}$} & \multirow{2}{*}{$\frac{h(7)}{F}$} & \multirow{2}{*}{$\frac{h(8)}{S}$} & \multirow{2}{*}{$\frac{h(9)}{N}$} & \multirow{2}{*}{$\frac{h(10)}{S}$} & \multirow{2}{*}{$\frac{\mathbf{h}(\mathbf{1 2})}{\mathrm{S}}$} & \multirow{2}{*}{$\frac{h(13)}{S}$} & \multicolumn{2}{|c|}{$h(14)$} & \multirow{2}{*}{$\frac{h(15)}{S}$} \\
\hline & $\mathbf{F}^{\mathbf{a}}$ & $\mathbf{S}$ & $\mathbf{N}$ & $\mathbf{F}$ & $\mathbf{S}$ & & $\mathbf{F}$ & $\mathbf{N}$ & & $\mathbf{F}$ & $\mathbf{N}$ & & & & & & & & $\mathbf{F}$ & $\mathbf{S}$ & \\
\hline 104 & $+^{\mathrm{b}}$ & + & $n a^{d}$ & + & + & - & - & na & - & - & na & - & - & - & na & - & - & - & - & - & - \\
\hline 147 & + & + & na & - & - & - & - & na & - & + & na & - & + & - & na & - & - & - & - & - & - \\
\hline 174 & + & $-c$ & $(+)$ & + & $(+)$ & - & - & - & - & $(+)$ & - & - & + & + & - & $(+)$ & - & + & - & - & - \\
\hline 301 & + & + & na & + & + & - & na & na & - & - & na & - & - & - & na & - & - & - & - & - & - \\
\hline 302 & + & + & na & + & + & - & na & na & - & - & na & + & - & - & na & - & - & - & - & - & - \\
\hline 405 & + & + & na & + & + & - & - & na & $(+)$ & - & na & - & - & - & na & - & - & - & - & - & - \\
\hline 413 & + & + & na & + & na & + & na & na & - & - & na & - & - & - & na & + & - & - & na & - & - \\
\hline $1066 \mathrm{e}$ & + & $(+)$ & + & - & - & - & - & - & - & - & - & + & + & + & - & $(+)$ & - & $(-)$ & - & - & - \\
\hline 1127 & + & + & na & - & - & - & - & na & - & - & na & + & + & + & na & $(+)$ & - & na & - & - & - \\
\hline 1634 & + & + & na & + & + & - & - & na & $(+)$ & - & na & - & - & - & na & - & - & - & - & - & - \\
\hline 1638 & + & + & na & + & + & - & - & na & $(+)$ & - & na & - & - & - & na & - & - & - & - & - & - \\
\hline 1639 & + & + & + & + & + & + & - & - & - & - & - & - & - & + & + & - & - & - & - & - & - \\
\hline 1680 & + & + & na & + & + & - & - & na & - & - & na & + & + & na & na & - & - & - & - & - & - \\
\hline 2199 & + & + & na & + & + & - & - & na & - & - & na & + & - & - & na & - & - & - & - & - & - \\
\hline 2408 & + & + & + & + & + & - & - & - & - & - & - & - & + & + & - & - & - & - & - & - & - \\
\hline 2409 & + & + & + & + & + & - & - & - & na & - & - & - & + & - & - & - & - & - & - & - & - \\
\hline 2410 & $(+)$ & - $^{\mathrm{c}}$ & na & na & - & - & na & na & - & - & na & - & - & - & na & - & - & - & - & - & - \\
\hline EU-B04 & + & + & + & + & + & - & - & - & - & - & - & - & - & - & - & + & - & - & - & - & - \\
\hline EU-B05 & + & + & + & + & + & - & na & - & - & - & - & - & na & - & - & - & - & - & - & - & - \\
\hline EU-D42a & + & + & + & + & + & - & - & - & - & - & - & + & - & - & - & + & - & - & - & - & - \\
\hline EU-NL05 & + & $(+)$ & + & - & - & - & - & - & - & - & - & + & + & + & - & $(+)$ & - & $(+)$ & - & - & - \\
\hline EU-NL19 & + & + & + & + & + & - & na & - & - & - & - & - & na & - & - & + & - & - & - & - & - \\
\hline EU-NL24 & + & + & + & + & na & na & na & + & na & na & - & + & + & - & - & - & - & - & na & - & - \\
\hline
\end{tabular}

${ }^{a}$ Location where the experiment was done: $\mathrm{F}=$ France, $\mathrm{S}=$ Switzerland, $\mathrm{N}=$ The Netherlands, with the inoculation technique: spraying (in white columns) or droplets (in gray columns).

b +: Compatible/susceptible, -: incompatible/resistant; (-): moderately resistant (considered as an incompatible reaction); (+): moderately susceptible (considered as a compatible reaction).

c See Figure 1

d Not assessed. 
the 23 isolates were avirulent on this host in at least one test (Table $3)$. On the other hosts, resistance was the rule and susceptibility the exception, as most hosts were infected by few isolates, and most isolates were capable of infecting only a few hosts (Table 3). Hosts $\mathrm{h}(12), \mathrm{h}(14)$, and $\mathrm{h}(15)$ were resistant to all the isolates tested. Hosts $h(2), h(3), h(4), h(5)$, and $h(13)$ were infected by one to three isolates, whereas hosts $h(6), h(7), h(8)$, and $h(10)$ were infected by six to nine isolates. In some cases, however, the compatible interaction involved weak susceptibility, e.g., isolates 405, 1634, and 1638 on $\mathrm{h}(4)$, isolates $174,1066 \mathrm{e}, 1127$, and EU-NL05 on $\mathrm{h}(10)$, and isolate EU-NL05 on h(13).

Sixteen different virulence patterns were observed out of the 23 tested isolates among 11 differential hosts that were overcome by at least one isolate. Generally, the isolates carried one to three virulences, with four isolates (1639, EU-NL24, 1066e, 1127) carrying four virulences and one isolate (EU-NL05) carrying five virulences (Table 4). Only isolate 2410 was avirulent on all the tested differential hosts. For isolate 174, the interpretation of the race status depended on the inoculation technique: it was virulent on five hosts using the spraying technique and on six hosts using the droplet technique. None of the isolates was virulent on all the hosts, which was to be expected on the grounds that except for Rvil and Rvi6, these genes have been used in neither temporal nor spatial dimensions for $V$. inaequalis strains to accumulate the virulences.

\section{Discussion}

Our study provides for the first time a description of the virulence pattern of a set of $V$. inaequalis isolates on 14 out of the updated set of 17 apple differential hosts (7). These well-characterized isolates can now in turn be used for the characterization of resistance in apple germplasm and for the understanding of the interaction in $V$. inaequalis/Malus pathosystem. The isolates can be requested from the INRA collection of Venturia spp. (IRHS, Angers, France) for a small fee.

Inoculation techniques. In the present study, we used two different inoculation techniques, spraying or droplets, which generally produced similar results. In a few cases, however, different results were obtained, e.g., with isolate 174 and h(5), where a compatible interaction was observed using the spray technique and an incompatible interaction using the droplet technique. The droplet method may overexpress the resistance cascade in an incompatible reaction due to a high concentration of effectors in a limited area of the leaf. The observation of pin-points on the universally susceptible host $\mathrm{h}(0)$ 'Gala' following droplet inoculation with isolates 174 and 2410 may be explained in the same way. It indicates the presence of a putative new resistance gene in this host, which previously was shown to carry QTLs on linkage groups 11 and 17 that reduce sporulation intensity (32). As no truly susceptible apple cultivar is expected to exist, there are no grounds to replace 'Gala' as host $\mathrm{h}(0)$.
Symptom development. In general, the identification of a compatible (abundant sporulation without macroscopic resistance reactions by the plant) or incompatible interaction (no symptoms or resistance reaction without sporulation) between a specific differential host and a $V$. inaequalis isolate was simple and clear as identified by the assignment of + and - , respectively (Table 3 ). However, in some cases, interpretation of the symptoms was not so straightforward. For example, isolate 1066e induced a resistance reaction on $\mathrm{h}(13)$, but sporulation was also evident; hence, this reaction was classified as (-) to indicate partial resistance. Similarly, the interactions with no resistance reaction and limited sporulation classified as $(+)$ were considered as compatible and the isolates as being virulent. This demonstrates that the resistance to susceptible scale is a continuum, as shown by Chevalier et al. (10). On $\mathrm{h}(4)$, the three isolates 405,1634 , and 1638 , all isolated from

Table 4. Virulence pattern of 23 isolates of Venturia inaequalis inoculated on 14 apple differential hosts

\begin{tabular}{lcc}
\hline Isolate & Race $^{\mathbf{a}}$ & Host not tested $^{\mathbf{b}}$ \\
\hline $2410=$ US4$^{\mathrm{c}}$ & $\left(-^{\mathrm{d}}\right)$ & $\mathrm{h}(3)$ \\
104 & $(1)$ & $\mathrm{h}(9)$ \\
301 & $(1)$ & $\mathrm{h}(3), \mathrm{h}(9)$ \\
EU-B05 & $(1)$ & $\mathrm{h}(7)$ \\
405 & $(1,4)$ & $\mathrm{h}(9)$ \\
1634 & $(1,4)$ & $\mathrm{h}(9)$ \\
1638 & $(1,4)$ & $\mathrm{h}(9)$ \\
302 & $(1,6)$ & $\mathrm{h}(3), \mathrm{h}(9)$ \\
2199 & $(1,6)$ & $\mathrm{h}(9)$ \\
$2409=1774-1$ & $(1,7)$ & $\mathrm{h}(4)$ \\
EU-B04 & $(1,10)$ & \\
EU-NL19 & $(1,10)$ & $\mathrm{h}(7)$ \\
413 & $(1,2,10)$ & $\mathrm{h}(3), \mathrm{h}(9)$ \\
1680 & $(1,6,7)$ & $\mathrm{h}(8), \mathrm{h}(9)$ \\
EU-D42a & $(1,6,10)$ & $\mathrm{h}(9)$ \\
147 & $(5,7)$ & \\
1639 & $(1,2,8,9)$ & $\mathrm{h}(2), \mathrm{h}(4)$ \\
$2408=\mathrm{NZ188B}$ & $(1,7,8)$ & \\
EU-NL24 & $(1,3,6,7)$ & \\
$1066 \mathrm{e}$ & $(6,7,8,10)$ & $\mathrm{h}(9), \mathrm{h}(13)$ \\
1127 & $(6,7,8,10)$ & \\
EU-NL05 & $(6,7,8,10,13)$ & \\
$174^{\mathrm{c}}$ & $(1,5,7,8,10,13)^{\mathrm{e}}$ or $(1,7,8,10,13)^{\mathrm{f}}$ & \\
\hline
\end{tabular}

${ }^{a}$ Description of the virulence pattern following the nomenclature described in Bus et al. (7).

${ }^{b}$ Differential hosts $h(11), h(16), h(17)$ were not tested in the present study; $\mathrm{h}(3), \mathrm{h}(4), \mathrm{h}(7), \mathrm{h}(8), \mathrm{h}(9)$, and $\mathrm{h}(13)$ were missing when indicated.

${ }^{c}$ Isolates 2410 and 174 were avirulent on the susceptible host $\mathrm{h}(0)$ with the droplet technique.

${ }^{\mathrm{d}}$ Isolate 2410 was avirulent on the tested hosts carrying major resistance genes.

e Virulence pattern following spraying technique for isolate 174 .

${ }^{\mathrm{f}}$ Virulence pattern following droplet technique for isolate 174 .

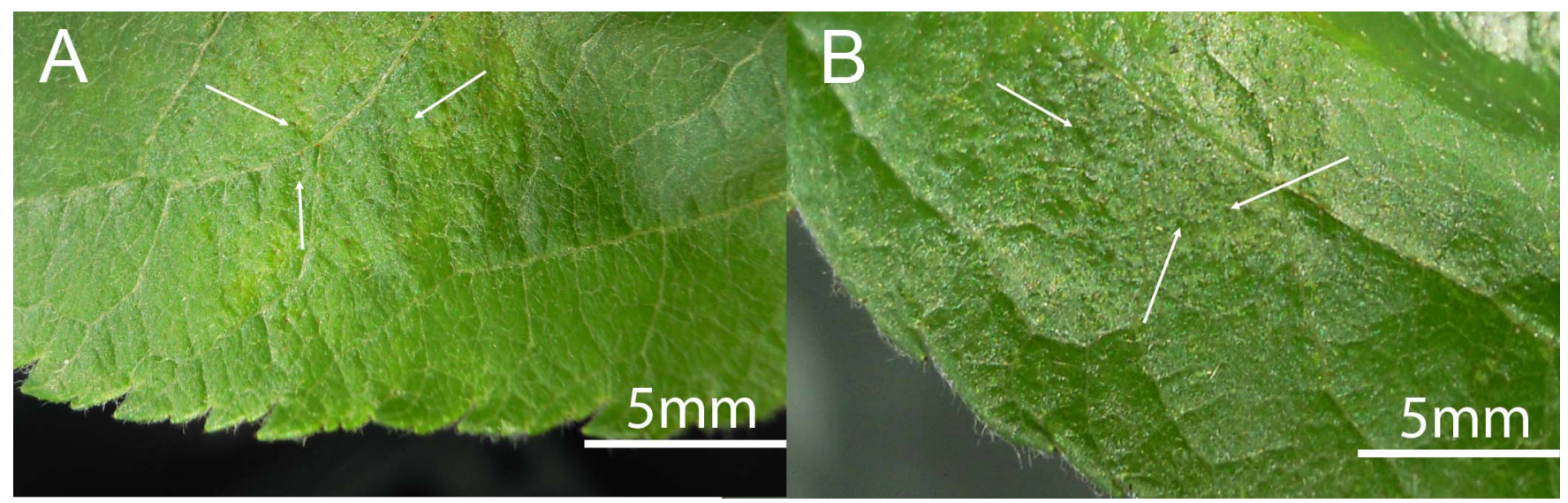

Fig. 1. Pin-points (some indicated by white arrows) on apple host $h(0)$ 'Gala' 3 weeks after inoculation with Venturia inaequalis isolate 174 (A) and 2410 (B) using the droplet technique. 
$\mathrm{h}(4)$, only showed moderate levels of sporulation (+). In the meantime, new race (4) isolates have been found that do appear to be completely virulent on h(4) (V. G. M. Bus, unpublished data), one of which may become the main reference race (4) isolate once it is fully characterized on the differential host set. Similarly, both weak and abundant sporulation was observed on $h(10)$ and $h(13)$. These differences in sporulation abundances may be due to quantitative variations in the expression of the virulence and resistance protein interactions and/or downstream signaling pathways (28). For $h(10)$, an additional reason may be the presence of a second gene (A. Patocchi and V. G. M. Bus, unpublished data).

Differential interactions. Except for isolates 2409 (1774-1) and 2410 (US4), our results confirmed the virulence status of the V. inaequalis isolates on the host(s) they were known to infect from previous studies $(1,6,8,18,19,24,26,30)$, with 11 of the differential hosts showing differential interactions in our study (Table 3): h(1), h(2), h(3), h(4), $h(5), h(6), h(7), h(8), h(9), h(10)$, and $h(13)$. To date, no virulent isolates have been reported for h(12) Hansen's baccata \#2, $h(14)$ 'Dülmener Rosenapfel,' and h(15) GMAL2473 (7,32), nor did any of the reference isolates infect these hosts in our experiments.

As expected, most isolates were compatible with 'Golden Delicious,' which agrees with the finding that $87 \%$ of a collection of European $V$. inaequalis isolates were found to be virulent on this host (26). A relatively large number of isolates virulent on $\mathrm{h}(6)$ were described in this study because they have become a major concern for all breeding programs around the world that rely on the Rvi6 gene for the development of apple scab-resistant cultivars. The seemingly widespread distribution of isolates virulent on $\mathrm{h}(8)$ is a new finding that was unexpected because the resistance Rvi8 does not appear to be present in $M . \times$ domestica. This resistance is prevalent in $M$. sieversii from central Asia (6), i.e., in the apple germplasm that was the progenitor for apple domestication (33). As $V$. inaequalis originated also from $M$. sieversii from central Asia (17), the complementary virulence allele may have been conserved in $V$. inaequalis populations.

Multigenic differential hosts. In the present study, LPG3-29 carrying only $R v i 7$ was selected from a 'Golden Delicious' $\times M$. floribunda 821 cross (1). It replaces $M$. floribunda clone 821 carrying Rvi6 as well as Rvi7, which made it difficult to determine the race status of most isolates for $R v i 7$ because it was masked by their incompatibility with Rvi6. LPG3-29 was successfully used in this study and is proposed as differential host $h(7)$ in future experiments, and will be added to the VINQUEST set for the worldwide pathotype monitoring.

Similar research to identify monogenic differential hosts is in progress for $h(3), h(10), h(12)$, and $h(14)$, which are known to carry more than one resistance gene $(7,27,32,35)$, hence the true virulence pattern of the tested isolates could not be determined for the specific genes of interest in these hosts.

Conclusions. In summary, a set of $V$. inaequalis isolates has been characterized for use as a tool in discovering and understanding new apple scab resistance genes and determining their GfG relationships. We have also proposed the new single gene accession LPG3-29 to replace the polygenic original host M. floribunda 821 as $\mathrm{h}(7)$. With nearly 1,000 NBS-LRR, and 575 LRR-kinase genes identified in the 'Golden Delicious' genome (33), more apple scab resistance genes remain to be discovered and new differential hosts will be defined in future, while new fully characterized isolates may have to be added. New virulences may be identified in the VINQUEST project (www.vinquest.ch) and their characterization may demonstrate new combinations of virulences. With well over 30 research teams participating or having expressed their interest to participate in this project, valuable information is being gathered that will assist apple breeders further in determining gene combinations that potentially provide durable resistance specific to each of the apple production regions.

\section{Acknowledgments}

We thank the Horticultural Experimental Unit 340449 and the INEM team (INRA, Angers-Nantes, France) and R. Blapp (Agroscope, Switzerland) for the production of apple plants. We thank Joanne Bowen and Reiny Scheper for their critical reviews of the manuscript. The research was partially supported by grants from the New Zealand Foundation for Research, Science \& Technology (contract C06X0810) and Plant \& Food Research Pipfruit Core programme 1433 .

\section{Literature Cited}

1. Bénaouf, G., and Parisi, L. 2000. Genetics of host-pathogen relationships between Venturia inaequalis races 6 and 7 and Malus species. Phytopathology 90:236-242.

2. Boone, D. M., and Keitt, G. W. 1957. Venturia inaequalis (CKE.) wint. XII. Genes controlling pathogenicity of wild-type lines. Phytopathology 47:403409.

3. Bowen, J. K., Mesarich, C. H., Bus, V. G. M., Beresford, R. M., Plummer, K. M., and Templeton, M. D. 2011. Venturia inaequalis: the causal agent of apple scab. Mol. Plant Pathol. 12:105-122.

4. Broggini, G. A. L., Bus, V. G. M., Parravicini, G., Kumar, S., Groenwold, R., and Gessler, C. 2011. Genetic mapping of 14 avirulence genes in an EUB04 $\times 1639$ progeny of Venturia inaequalis. Fungal Genet. Biol. 48:166 176.

5. Bus, V. G. M. 2006. Differential host-pathogen interactions of Venturia inaequalis and Malus. PhD Thesis, University of Auckland, New Zealand.

6. Bus, V. G. M., Laurens, F. N. D., van de Weg, W. E., Rusholme, R. L. Rikkerink, E. H. A., Gardiner, S. E., Bassett, H. C. M., Kodde, L. P., and Plummer, K. M. 2005. The $V h 8$ locus of a new gene-for-gene interaction between Venturia inaequalis and the wild apple Malus sieversii is closely linked to the Vh2 locus in Malus pumila R12740-7A. New Phytol. 166:1035-1049.

7. Bus, V. G. M., Rikkerink, E. H. A., Caffier, V., Durel, C. E., and Plummer, K. M. 2011. Revision of the nomenclature of the differential host-pathogen interactions of Venturia inaequalis and Malus. Annu. Rev. Phytopathol. 49:391-413.

8. Bus, V. G. M., Rikkerink, E. H. A., van de Weg, W. E., Rusholme, R. L., Gardiner, S. E., Bassett, H. C. M., Kodde, L. P., Parisi, L., Laurens, F. N. D., Meulenbroek, E. J., and Plummer, K. M. 2005. The Vh2 and Vh4 scab resistance genes in two differential hosts derived from Russian apple R12740-7A map to the same linkage group of apple. Mol. Breeding 15:103116.

9. Chapman, K. S., Sundin, G. W., and Beckerman, J. L. 2011. Identification of resistance to multiple fungicides in field populations of Venturia inaequalis. Plant Dis. 95:921-926.

10. Chevalier, M., Lespinasse, Y., and Renaudin, S. 1991. A microscopic study of the different classes of symptoms coded by the $V f$ gene in apple for resistance to scab (Venturia inaequalis). Plant Pathol. 40:249-256.

11. Chowda-Reddy, R. V., Sun, H., Hill J. H., Poysa, V., and Wang, A. 2011. Simultaneous mutations in multi-viral proteins are required for Soybean mosaic virus to gain virulence on Soybean genotypes carrying different $R$ genes. PLoS ONE 6:e28342.

12. Durel, C. E., Calenge, F., Parisi, L., van de Weg, W. E., Kodde, L. P., Liebhard, R., Gessler, C., Thiermann, M., Dunemann, F., Gennari, F., Tartarini, S., and Lespinasse, Y. 2004. An overview of the position and robustness of scab resistance QTLs and major genes by aligning genetic maps of five apple progenies. Acta Hortic. 663:135-140.

13. Flor, H. H. 1956. The complementary genic systems in flax and flax rust. Adv. Genet. 8:29-54.

14. Galli, P., Broggini, G. A. L., Kellerhals, M., Gessler, C., and Patocchi, A. 2010. High-resolution genetic map of the Rvi15 ( Vr2) apple scab resistance locus. Mol. Breeding 26:561-572.

15. Gessler, C., Patocchi, A., Sansavini, S., Tartarani, S., and Gianfranceschi, L. 2006. Venturia inaequalis resistance in apple. Crit. Rev. Plant Sci. 25:473503.

16. Gladieux, P., Guerin, F., Giraud, T., Caffier, V., Lemaire, C., Parisi, L., Didelot, F., and Le Cam, B. 2011. Emergence of novel fungal pathogens by ecological speciation: importance of the reduced viability of immigrants. Mol. Ecol. 20:4521-4532.

17. Gladieux, P., Zhang, X. G., Afoufa-Bastien, D., Valdebenito Sanhueza, R. M., Sbaghi, M., and Le Cam, B. 2008. On the origin and spread of the scab disease of apple: out of central Asia. PloS ONE 1:e1455.

18. Guillaumès, J., Chevalier, M., and Parisi, L. 1995. Studies on the relationship between Venturia inaequalis and Malus $\times$ domestica in vitroplants. Can. J. Plant Pathol. 17:305-311.

19. Hernandez, C. F. D., Parisi, L., and Lespinasse, Y. 1994. Inheritance of the avirulence trait in an isolate of Venturia inaequalis (Cke.) Wint. on Golden Delicious apple (Malus $\times$ domestica Borkh.) cultivar. Rev. Mex. Fitopatol. 12:31-34.

20. Jones, J. D. G., and Dangl, J. L. 2006. The plant immune system. Nature 444:323-329.

21. Laurens, F., Chevalier, M., Dolega, E., Gennari, F., Goerre, M., Fischer, C., Kellerhals, M., Lateur, M., Lefrancq, B., Parisi, L., Schouten, H. J., and Tartarini, S. 2004. Local european cultivars as sources of durable scab resistance in apple. Acta Hortic. 663:115-121.

22. Lê Van, A., Durel, C. E., Le Cam, B., and Caffier, V. 2011. The threat of wild habitat to scab resistant apple cultivars. Plant Pathol. 60:621-630. 
23. Olivera, P. D., Pretorius, Z. A., Badebo, A., and Jin, Y. 2013. Identification of resistance to races of Puccinia graminis f. sp tritici with broad virulence in triticale $(\times$ Triticosecale). Plant Dis. 97:479-484.

24. Parisi, L., and Lespinasse, Y. 1996. Pathogenicity of Venturia inaequalis strains of race 6 on apple clones (Malus sp.). Plant Dis. 80:1179-1183.

25. Parisi, L., Durel, C. E., and Laurens, F. 2000. First report on the presence of Venturia inaequalis race 7 in French apple orchards. IOBC wprs Bulletin 23:99-104.

26. Parisi, L., Fouillet, V., Schouten, H. J., Groenwold, R., Laurens, F., Didelot, F., Evans, K., Fischer, C., Gennari, F., Kemp, H., Lateur, M., Patocchi, A., Thissen, J., and Tsipouridis, C. 2004. Variability of the pathogenicity of Venturia inaequalis in Europe. Acta Hortic. 663:107-113.

27. Patocchi, A., Frei, A., Frey, J. E., and Kellerhals, M. 2009. Towards improvement of marker assisted selection of apple scab resistant cultivars: Venturia inaequalis virulence surveys and standardization of molecular marker alleles associated with resistance genes. Mol. Breeding 24:337-347.

28. Poland, J. A., Balint-Kurti, P. J., Wisser, R. J., Pratt, R. C., and Nelson, R. J. 2009. Shades of gray: the world of quantitative disease resistance. Trends Plant Sci. 4:21-29.

29. Roberts, A. L., and Crute, I. R. 1994. Apple scab resistance from Malus floribunda $821(\mathrm{Vf})$ is rendered ineffective by isolates of Venturia inaequalis from Malus floribunda. Norw. J. Agric. Sci. 17:403-406.

30. Schnabel, G., and Parisi, L. 1997. Sensitivity of Venturia inaequalis to five DMI fungicides, including the new triazole fluquinconazole, and to pyrimethanil. J. Plant Dis. Prot. 104:36-46.

31. Schouten, H. J., Brinkhuis, J., van der Burgh, A., Schaart, J. G., Groenwold, R., Broggini, G. A. L., and Gessler, C. 2014. Cloning and functional characterization of the Rvi15 ( $\mathrm{Vr} 2)$ gene for apple scab resistance. Tree Genet. Ge- nomes 10:251-260

32. Soufflet-Freslon, V., Gianfranceschi, L., Patocchi, A., and Durel, C. E. 2008. Inheritance studies of apple scab resistance and identification of Rvi14, a new major gene that acts together with other broad-spectrum QTL. Genome 51:657-667.

33. Velasco, R., Zharkikh, A., Affourtit, J., Dhingra, A., Cestaro, A., Kalyanaraman, A., Fontana, P., Bhatnagar, S. K., Troggio, M., Pruss, D., Salvi, S., Pindo, M., Baldi, P., Castelletti, S., Cavaiuolo, M., Coppola, G., Costa, F., Cova, V., Dal Ri, A., Goremykin, V., Komjanc, M., Longhi, S., Magnago, P., Malacarne, G., Malnoy, M., Micheletti, D., Moretto, M., Perazzolli, M., SiAmmour, A., Vezzulli, S., Zini, E., Eldredge, G., Fitzgerald, L. M., Gutin, N., Lanchbury, J., Macalma, T., Mitchell, J. T., Reid, J., Wardell, B., Kodira, C., Chen, Z., Desany, B., Niazi, F., Palmer, M., Koepke, T., Jiwan, D. Schaeffer, S., Krishnan, V., Wu, C., Chu, V. T., King, S. T., Vick, J., Tao, Q. Mraz, A., Stormo, A., Stormo, K., Bogden, R., Ederle, D., Stella, A., Vecchietti, A., Kater, M. M., Masiero, S., Lasserre, P., Lespinasse, Y., Allan, A. C., Bus, V., Chagné, D., Crowhurst, R. N., Gleave, A. P., Lavezzo, E., Fawcett, J. A., Proost, S., Rouzé, P., Sterck, L., Toppo, S., Lazzari, B., Hellens, R. P., Durel, C. E., Gutin, A., Bumgarner, R. E., Gardiner, S. E., Skolnick, M., Egholm, M., Van de Peer, Y., Salamini, F., and Viola, R. 2010. The genome of the domesticated apple (Malus $\times$ domestica Borkh.). Nat. Genet. 42:833-839

34. Whitaker, V. M., Debener, T., Roberts, A. V., and Hokanson, S. C. 2010. A standard set of host differentials and unified nomenclature for an international collection of Diplocarpon rosae races. Plant Pathol. 59:745-752.

35. Williams, E. B., and Shay, J. R. 1957. The relationship of genes for pathogenicity and certain other characters in Venturia inaequalis (Cke.) Wint. Genetics 42:704-711. 